\title{
Chapter 2 \\ Permanent Migrants and Cross-Border Workers: The Effects on the Host Country
}

\subsection{Introduction}

When we use the word "migrants," we tend to disregard the variation in their behavior. We can in fact classify migrants according to length of stay, purpose of migration, geographical origin, or historical background. In this paper, I focus on the time interval of migration and distinguish the three types of migrants: permanent migrants, temporary migrants, and cross-border workers.

Permanent migrants decide to migrate when they are young, and after migration they call their family to join them in the host country as soon as possible. This type of immigrant predominates in Australia, Canada, and the United States. Temporary migrants cross the border in order to work for a certain period when they are young and go back to their home countries after they earn enough money. ${ }^{1}$ The third type is the cross-border worker. Due to the decrease in transportation costs and the progress of interregional economic integration, the number of cross-border workers is growing rapidly. Nowadays, they may be seen in many parts of the world. These include workers from Malaysia to Singapore, from Palestine to Israel, and from France to Switzerland, Germany, and Luxembourg. de Falleur and Vandeville (1994) estimated the number of cross-border workers in the European Union to be more than 316,000 in 1990 . According to their studies, the main reason why workers want to work in a neighboring country is the substantial difference in wages, despite

This paper was originally published by the Journal of Regional Science as an article in its vol. 38 (1999) issue.

${ }^{1}$ Migrants repeating their migratory trips are called periodic migrants. The length of each stay in the host country may be several years or several seasons. Those Mexicans who live near the border and come to the United States many times during their lifetime belong in this category. Concerning the place where they spend their income, we may regard periodic migrants as a kind of temporary migrants. See the final section for the analysis of this type of migration. 
small differences in culture and language between those countries; and the primary reason why these workers wish to return home periodically is the difference in tax systems.

Many studies in the regional science literature concern factors affecting migration patterns. ${ }^{2}$ Borjas (1994) surveyed empirical studies on the elasticity of native wages with respect to the number of immigrants. However, there are very few studies comparing the economic effects caused by various types of international immigration. In this paper, I shall initially consider two extreme types of workerspermanent migrants and cross-border workers-and compare their impacts on the welfare of the host country. In this paper, the distinction between permanent migrants and cross-border workers is analytically identical to the case of immigration with no remittance versus the case of complete repatriation of migrant income. ${ }^{3}$ I will consider the effect of the third type of migrant, temporary migrants, in the concluding section.

By adopting the two-commodity, two-factor model where one commodity is a nontraded good, Rivera-Batiz (1982, 1983, 1984), Lundahl (1985), Djajić (1986), Quibria (1988,1989), and Thompson (1984) investigated theoretically the economic effects of labor outflow on the source country. ${ }^{4}$ Among them, Rivera-Batiz (1982) was a pioneer, and he concludes that emigration (without remittance) harms those left behind. Djajić (1986) concluded that if remittance by emigrants is large enough, emigration could be beneficial for those left behind because remittance serves as a means of restoring the lost opportunity to trade between emigrants and the remaining residents of the source country. However, these papers did not study the effects of immigration on the host country. Following Kondoh (1999), this chapter is an attempt to fill this gap, and the results are not directly obtainable from the papers mentioned above. In particular, although the effect of remittance on the welfare of the source country is usually positive (see Djajic 1986), the welfare effect of

\footnotetext{
${ }^{2}$ Concerning return migration, Mueller (1982) and Bohning (1984) concluded that return migration took place when migrants' target saving levels were satisfied. Waldorf and Esparza (1991) emphasized the importance of assimilation in the host country and strong ties to the home country. Kau and Sirmans (1977) analyzed the influence of information cost and uncertainty on migration pattern. Chau (1997) emphasized the role of migrant networks in determining patterns of migration. Using a theoretical approach, Hill (1987) analyzed periodic migrants' behavior, and Djajić and Milboune (1988) analyzed legal temporary migrants' optimal behavior.

${ }^{3}$ Various authors have tried to explain certain aspects of a migrant's behavior (e.g., whether he or she decides to migrate or not, chooses to be a permanent migrant or a temporary migrant). Djajić and Milboune (1988) studied the optimal behavior of a temporary migrant who can endogenously choose his optimal staying period. On the other hand, Djajić (1989) and Bhagwati et al. (1984) studied the "gastarbeiter system" in which the staying period of a migrant is arranged beforehand. Future uncertainty may also affect the behavior of migrants. McCall and McCall (1987), Dustmann (1997), and O'Connell (1997) investigated the role of uncertainty. Finally, Bhagwati and Hamada (1982) paid attention to the role of education.

${ }^{4}$ Lundahl (1985), Thompson (1984), Rivera-Batiz (1984), and Quibria (1989) analyzed the real income of each factor in the home country. Their results, the counterparts of our Proposition 2.1, items (1) and (2), which apply to the host country, are consistent with our results.
} 
remittance on the host country (considered in this paper) turns out to be positive when the nontraded good is labor-intensive and negative when the nontraded good is capital-intensive. ${ }^{5}$

In Sect. 2.2, we present the model. I devote Sects. 2.3 and 2.4 to the analysis of prices and welfare, respectively. The last section contains my concluding remarks.

\subsection{The Model}

Consider a small open country in which there are two goods and two factors, labor and capital. One good is tradable and the other is nontradable. It is assumed that there is an inflow of immigrants to this country, while capital is assumed to be internationally immobile.

The production functions of the traded good and nontraded good are, respectively,

$$
\begin{aligned}
& T=T\left(L_{T}, K_{T}\right), \\
& N=N\left(L_{N}, K_{N}\right),
\end{aligned}
$$

where $L_{T}$ and $K_{T}$ are the labor input for the production of the traded good and the nontraded good, respectively. Similarly, $K_{T}$ and $K_{N}$ are capital inputs for the production of the traded and the nontraded good, respectively. Both functions are assumed to be linearly homogeneous as well as strictly quasi-concave.

For the moment, suppose there are two kinds of labor inflows into this country. One is permanent labor movement and the other is cross-border periodic labor movement. Under the assumptions of perfect competition and full employment, we obtain the following equations:

$$
\begin{gathered}
p_{N} N^{L}=T^{L}=w \\
p_{N} N^{K}=T^{K}=r \\
L_{T}+L_{N}=L+L_{M}+L_{B} \\
K_{T}+K_{N}=K
\end{gathered}
$$

\footnotetext{
${ }^{5}$ Some recent papers also studied about remittance of immigrants. Shen et al. (2010) developed a model to study the effects of migration and remittances on inequality in the origin communities. Mandelman and Zlate (2012) used data on border enforcement and macroeconomic indicators from the United States and Mexico to estimate a two-country business cycle model of labor migration and remittances.
} 
where $N^{L}=\partial N / \partial L_{N}$, and $T^{L}, N^{K}$, and $T^{K}$ are defined in a similar way. Taking the traded good as numeraire, we denote the price of the nontraded good, the wage rate, and the rental price by $p_{N}, w$, and $r$, respectively. $L_{M}$ and $L_{B}$ are the inflows of permanent migrants and cross-border workers, respectively. $L$ and $K$ are the endowments of labor and capital in the host country, and both are assumed to be given and constant. Equations 2.1 and 2.2 express the equilibrium conditions of producers. Equations 2.3 and 2.4 are the equilibrium conditions of factor markets.

As is seen in Eqs. 2.1, 2.2, 2.3, and 2.4, the supply functions of the two goods depend upon the relative price, $p_{N}$; the factor endowments, $L$ and $K$; and the inflow of the two types of migrants, $L_{M}$ and $L_{B}$. Thus, because $L$ and $K$ are given and constant, we can display the supply functions of the traded and nontraded goods as

$$
\begin{aligned}
& S_{T}=S_{T}\left(p_{N}, L_{M}, L_{B}\right), \\
& S_{N}=S_{N}\left(p_{N}, L_{M}, L_{B}\right) .
\end{aligned}
$$

Next we introduce the domestic demand functions

$$
\begin{aligned}
& D_{T}=D_{T}\left(p_{N}, Y\right), \\
& D_{N}=D_{N}\left(p_{N}, Y\right),
\end{aligned}
$$

where $D_{T}$ and $D_{N}$ are the demands for the traded and nontraded goods in the host country, respectively. ${ }^{6} Y$ is the total income spent in this country and algebraically defined as

$$
\begin{gathered}
Y \equiv Y_{K}+Y_{L}+Y_{M}, \\
Y_{K} \equiv r K=T^{K} K, \\
Y_{L} \equiv w L=T^{L} L, \\
Y_{M} \equiv w L_{M}=T^{L} L_{M},
\end{gathered}
$$

where $Y_{K}, Y_{L}$, and $Y_{M}$ denote the income of capital, the income of native labor, and the income of permanent migrants. Permanent migrants move with their families so all their income is sent for consumption in the host county. But cross-border workers spend their earnings mainly in their home country. For simplification, we ${ }^{6}$ This kind of demand function may be introduced if it is assumed that income earned by native
labor and immigrants and income from capital have the same influence on demand. 
assume that all of their income is spent in the home country. Therefore, $Y$, which affects $D_{T}$ and $D_{N}$, contains the income of permanent migrants but excludes the income of cross-border workers. Both goods are supposed to be normal, so that $D_{T}^{Y} \equiv \partial D_{T} / \partial Y>0$ and $D_{N}^{Y} \equiv \partial D_{N} / \partial Y>0$.

Now consider the equilibrium conditions for the goods markets. One equilibrium condition may be omitted by Walras' law, we adopt the condition of the nontraded goods market. Thus, we have

$$
D_{N}\left(p_{N}, Y\right)=S_{N}\left(p_{N}, L_{M}, L_{B}\right)
$$

To satisfy the market-clearing condition, net foreign demand for the host-country export of the traded good must equal the wages earned by cross-border workers. In other words, cross-border workers are deemed to receive their wages in the form of the traded good. In this general equilibrium system, Eqs. 2.1, 2.2, 2.3, 2.4, and 2.5 determine seven endogenous variables $w, r, L_{T}, L_{N}, K_{T}, K_{N}$, and $p_{N}$ if $K, L, L_{M}$, and $L_{B}$ are given exogenously.

\subsection{The Analysis of Price Responses}

In this section, we investigate the effects of an increase in permanent migrants and cross-border workers on prices in the host country.

Differentiation of Eq. 2.5 with respect to $p_{N}$ and $L_{M}$ yields

$$
\frac{d p_{N}}{d L_{M}}=p_{N}^{M}=\frac{S_{N}^{L}-D_{N}^{Y}\left(\partial Y / \partial L_{M}\right)}{D_{N}^{p}-S_{N}^{p}+D_{N}^{Y}\left(\partial Y / \partial p_{N}\right)},
$$

where $S_{N}^{L} \equiv \partial S_{N} / \partial L_{M}=\partial S_{N} / \partial L_{B}, D_{N}^{p} \equiv \partial D_{N} / \partial p_{N}$, and $S_{N}^{p} \equiv \partial S_{N} / \partial p_{N}{ }^{7}$

Now consider the following Walrasian price adjustment process:

$$
\dot{p}_{N}=D_{N}\left(p_{N}, Y\right)-S_{N}\left(p_{N}, L_{M}, L_{B}\right) \text {. }
$$

For a comparative static analysis to be meaningful, equilibria must be stable. The stability condition $d \dot{p}_{N} / d p_{N}<0$ ensures that the denominator of Eq. 2.6 is negative. Furthermore, $Y \equiv w\left(L+L_{M}\right)+r K$, and when $p_{N}$ is unchanged, $w$ and $r$ are also unchanged due to the factor-price-equalization theorem. Therefore, it is shown that $\partial Y / \partial L_{M}=w$. In addition, according to the Appendix or the Rybczynski theorem, $S_{N}^{L}>0$ if the nontraded good is labor-intensive and $S_{N}^{L}<0$ if it is capital-intensive. It follows that from Eq. 2.6, $d p_{N} / d L_{M}>0$ if the nontraded good is capital-intensive.

Consider the case in which the nontraded good is labor-intensive. Both goods are assumed to be normal, so it is evident that $0<p_{N} D_{N}^{Y}<1$. In addition,

\footnotetext{
${ }^{7}$ Equation 2.6 is valid for equilibrium values of $L_{M}$ and $p_{N}$.
} 
the Appendix 1 shows that $L_{N}^{M}\left(=L_{N}^{B}\right) \equiv \partial L_{N} / \partial L_{M}>1$ and $K_{N}^{M}\left(=K_{N}^{B}\right) \equiv$ $\partial K_{N} / \partial L_{M}>0$. Making use of these facts, we can verify that $\left|D_{N}^{Y} w\right|=\left|p_{N} D_{N}^{Y} N^{L}\right|<$ $\left|N^{L} L_{N}^{M}\right|<\left|N^{L} L_{N}^{M}+N^{L} K_{N}^{M}\right|=\left|S_{N}^{L}\right|$. Because $S_{N}^{L}>0$, we finally obtain $p_{N}^{M}<0$.

Next, differentiation of Eq. 2.5 with respect to $p_{N}$ and $L_{B}$ yields

$$
\frac{d p_{N}}{d L_{B}}=p_{N}^{B}=\frac{S_{N}^{L}}{D_{N}^{p}-S_{N}^{p}+D_{N}^{Y}\left(\partial Y / \partial p_{N}\right)} .
$$

Now compare Eqs. 2.6 and 2.7. Because $D_{N}^{Y} w>0, S_{N}^{L}-D_{N}^{Y} w<S_{N}^{L}<0$ if the nontraded good is capital-intensive, and because $D_{N}^{p}-S_{N}^{p}+D_{N}^{Y}\left(\partial Y / \partial p_{N}\right)<0$, we can conclude that $p_{N}^{M}>p_{N}^{B}>0$. If the nontraded good is labor-intensive, by a similar argument, $S_{N}^{L}>S_{N}^{L}-D_{N}^{Y} w>0$ and $p_{N}^{B}<p_{N}^{M}<0$ are obtained.

In the analysis of Lundahl (1985) whose focus is on the source country of migration, the sign of $d p_{N} / d L_{M}$ is ambiguous if the nontraded good is capitalintensive. This is because the difference between the source country's wage and the host country's wage is responsible for the ambiguity of the effect of migrant outflow on the national income of the source country. This analysis is concerned with the host country so such ambiguity does not occur. ${ }^{8}$

Using the above results, we proceed with the analysis of the effect of a change in the inflow of workers on factor prices. Through a direct computation (combined with $\partial w / \partial L_{M}=0$, as asserted by the factor-price-equalization theorem), we have

$$
\begin{aligned}
\frac{d w}{d L_{M}} & =\frac{\partial w}{\partial L_{M}}+\frac{\partial w}{\partial p_{N}} \frac{d p_{N}}{d L_{M}}=\frac{\partial w}{\partial p_{N}} \frac{d p_{N}}{d L_{M}} \\
& =\left[T^{L L} \frac{d L_{T}}{d p_{N}}+T^{L K} \frac{d K_{T}}{d p_{N}}\right] p_{N}^{M} \\
& =\frac{k_{T} k_{N}\left[\left(k_{T} / k_{N}-1\right) N^{L}+\left(k_{T}-k_{N}\right) N^{K}\right] p_{N}^{M}}{\left(k_{T}-k_{N}\right)^{2}}
\end{aligned}
$$

where $k_{T} \equiv K_{T} / L_{T}, k_{N} \equiv K_{N} / L_{N}, T^{L L} \equiv \partial T^{L} / \partial L_{T}$ and $T^{L K} \equiv \partial T^{L} / \partial K_{T}$. (Detailed calculation is contained in the Appendix 1.) Hence, we have $d w / d L_{M}<0$ as long as $k_{T} \neq k_{N}$, because the above results show that the sign of $p_{N}^{M}$ is opposite to that of $k_{T}-k_{N}$.

\footnotetext{
${ }^{8}$ Ottaviano and Peri (2012) empirically studied the effects of immigration on wages of US-born workers and concluded it should be positive because positive effects on high-educated workers dominate negative effects on low-educated workers. Dustmann et al. (2013) studied the effects of immigration on the distribution of native wages.
} 
In a similar manner,

$$
\begin{gathered}
\frac{d w}{d L_{B}}=\frac{k_{T} k_{N}\left[\left(k_{T} / k_{N}-1\right) N^{L}+\left(k_{T}-k_{N}\right) N^{K}\right] p_{N}^{B}}{\left(k_{T}-k_{N}\right)^{2}}, \\
\frac{d r}{d L_{M}}=\frac{-k_{T} k_{N}\left[\left(1 / k_{N}-1 / k_{T}\right) N^{L}+\left(1-k_{N} / k_{T}\right) N^{K}\right] p_{N}^{M}}{\left(k_{T}-k_{N}\right)^{2}}, \\
\frac{d r}{d L_{B}}=\frac{-k_{T} k_{N}\left[\left(1 / k_{N}-1 / k_{T}\right) N^{L}+\left(1-k_{N} / k_{T}\right) N^{K}\right] p_{N}^{B}}{\left(k_{T}-k_{N}\right)^{2}} .
\end{gathered}
$$

From the above equations, as long as $k_{T} \neq k_{N}$, the sign of Eq. 2.9 is negative, and those of Eqs. 2.10 and 2.11 are positive. Furthermore, using the results on $p_{N}^{M}$ and $p_{N}^{B}$, we obtain $d w / d L_{M}<d w / d L_{B}<0$ and $d r / d L_{M}>d r / d L_{B}>0$ if the nontraded good is capital-intensive. If the nontraded good is labor-intensive, we have $d w / d L_{B}<d w / d L_{M}<0$ and $d r / d L_{B}>d r / d L_{M}>0$.

The following proposition summarizes the above results:

\section{Proposition 2.1}

1. If the nontraded good is capital-intensive (labor-intensive), then an increase in the inflow of either type of immigration raises (lowers) the relative price of the nontraded good.

2. An increase of the inflow of either type of immigration lowers the wage rate and raises the rental price. ${ }^{9}$

3. If the nontraded good is capital-intensive (labor-intensive), the responses of the relative price of the nontraded good and of both factor prices to an increase in the inflow of permanent migrants are larger (smaller) than those caused by an increase in the inflow of cross-border workers.

\subsection{The Analysis of Welfare}

I now focus on the analysis of welfare in the host country. ${ }^{10}$ To this end, let the aggregate utility function, which represents the welfare of nonimmigrants (native capital owners and native workers), be $U^{*}=U^{*}\left(D_{N}^{*}, D_{T}^{*}\right)$, where $D_{N}^{*}$ and $D_{T}^{*}$ are the demands of the nontraded and traded good by nonimmigrants, respectively, and we assume $U^{*}=U^{*}\left(D_{N}^{*}, D_{T}^{*}\right)$ to be strictly quasi-concave. ${ }^{11}$

\footnotetext{
${ }^{9}$ This follows directly from the magnification effect in Jones (1965).

${ }^{10}$ To obtain the clear conclusions of this section, I have benefited from the helpful suggestions by anonymous referees of the Journal of Regional Science.

${ }^{11}$ Assuming that capital owners, native workers, and permanent migrants have identical homothetic preferences
} 
Differentiate the utility function totally, so that

$$
d U^{*}=\frac{\partial U^{*}}{\partial D_{N}^{*}} d D_{N}^{*}+\frac{\partial U^{*}}{\partial D_{T}^{*}} d D_{T}^{*} .
$$

Because $\left(\partial U^{*} / \partial D_{N}^{*}\right) /\left(\partial U^{*} / \partial D_{T}^{*}\right)=p_{N}$, Eq. 2.12 can be rewritten as

$$
\frac{d U^{*}}{\left(\partial U^{*} / \partial D_{T}^{*}\right)}=p_{N} d D_{N}^{*}+d D_{T}^{*}
$$

On the other hand, note that $U^{*}$ is maximized subject to the budget constraint given by

$$
p_{N} D_{N}^{*}+D_{T}^{*}=p_{N} N^{*}+T^{*}
$$

where $N^{*}$ and $T^{*}$ indicate the output of the traded and nontraded goods that a competitive economy consisting only of nonimmigrants (working with the capital they own) would produce given a price of $p_{N}$. Bhagwati and Brecher (1980) show that under reasonable conditions, which are assumed to hold here, this will represent the effective budget constraint faced by nonmigrants in the full economy. An application of this approach to an environment similar to that here is provided in Rivera-Batiz (1982). By differentiating Eq. 2.14, we obtain

$$
p_{N} d D_{N}^{*}+D_{N}^{*} d p_{N}+d D_{T}^{*}=p_{N} d N^{*}+N^{*} d p_{N}+d T^{*},
$$

and substituting Eq. 2.15 into Eq. 2.13, we can determine the factors that give rise to a change in $U^{*}$,

$$
\frac{d U^{*}}{\left(\partial U^{*} / \partial D_{T}^{*}\right)}=\left(N^{*}-D_{N}^{*}\right) d p_{N}+p_{N} d N^{*}+d T^{*}
$$

Because $N^{*}$ and $T^{*}$ are output combinations on the nonimmigrant production possibility frontier chosen when price is $p_{N}$, we know that $d T^{*} / d N^{*}=-p_{N}$ so that $p_{N} d N^{*}+d T^{*}=0$. We find that the only factor that can change $U^{*}$ is a change in the price ratio. Therefore, we may conclude:

$$
\begin{aligned}
& \frac{1}{\left(\partial U^{*} / \partial D_{T}^{*}\right)} \frac{d U^{*}}{d L_{M}}=\left(N^{*}-D_{N}^{*}\right) p_{N}^{M} \\
& \frac{1}{\left(\partial U^{*} / \partial D_{T}^{*}\right)} \frac{d U^{*}}{d L_{B}}=\left(N^{*}-D_{N}^{*}\right) p_{N}^{B}
\end{aligned}
$$

On the other hand, as shown in Sect. 2.3, if the nontraded good is capital (labor)intensive, immigration raises (lowers) the relative price of the nontraded good. As a result, similar to Rivera-Batiz (1982), the nonimmigrants increase (decrease) their production of the nontraded good and start or extend trading with the immigrants 
even though the aggregate production of the nontraded good decreases (increases). Therefore, if $k_{T}>(<) k_{N}$, because $N^{*}>(<) D_{N}^{*}$ and $p_{N}^{B}<p_{N}^{M}<0\left(p_{N}^{M}>p_{N}^{B}>0\right)$, we finally obtain $\frac{d U^{*}}{d L_{B}}>\frac{d U^{*}}{d L_{M}}>0\left(\frac{d U^{*}}{d L_{M}}>\frac{d U^{*}}{d L_{B}}>0\right)$.

The following proposition summarizes the welfare aspects of an increase in migration.

\section{Proposition 2.2}

1. A marginal increase in the inflow of either type of foreign workers gives rise to an aggregate welfare gain of natives (non-immigrants) in the host country. ${ }^{12}$

2. If the nontraded good is labor (capital) intensive, the inflow of permanent migrants brings forth a smaller (larger) aggregate increase on the non-migrants' welfare than does the inflow of cross-border workers.

Djajić (1986) studied the role of remittance in determining the effects of migration on the welfare of the remaining residents in the source country. He concluded that the inflow of remittance is usually beneficial to remaining residents, and if it exceeds a certain critical amount, they can enjoy a higher level of utility than in the absence of migration.

Our analysis is similar to Djajić (1986). However, for the nonimmigrants in the host country, whether remittance is beneficial (i.e., whether cross-border workers are preferable to permanent migrants) depends on the factor intensity of the two goods. If the nontraded good is labor-intensive, both countries will welcome migrants' remittances, and, moreover, if the source-country residents receive a sufficiently large remittance, both countries will enjoy economic gains from migration.

\subsection{Concluding Remarks}

In conclusion, we offer two main points. First, recall that in the introduction, we mentioned three types of migrants but have ignored the case of temporary migrants in this paper. The temporary migrants' behavior involves two important aspects. The first aspect is that they remit a part of their income to the home countries where their families remain. The second aspect is that they will return to their home countries after they earn enough money. Considering these aspects, we argue that their effects on the host country take a middle position between those of permanent migrants and cross-border workers. To see this, we introduce a temporary migrant's utility function as $v\left(p_{N},(1-\alpha) w\right)+v\left(p_{N}^{*}, \alpha w\right)$, where $p_{N}^{*}$ denotes the relative price of the nontraded good in the home country and $\alpha(0<\alpha<1)$ denotes the fraction of income sent to the home country. A cross-border worker (a permanent migrant) is the special case where $\alpha=1(\alpha=0)$. This means that $n$ temporary migrants

\footnotetext{
${ }^{12}$ Wong (1995) studied the welfare effects of international migration by GDP function approach. Detailed information is included in Appendix 2.
} 
are equivalent to a combination of $\alpha n$ cross-border workers and (1- $\alpha) n$ permanent migrants, in terms of economic influences on the host country. It follows that the economic effects of periodic migrants are essentially similar to those of temporary migrants (the difference being only the number of trips; the consumption of periodic migrants also occurs in both countries).

Our second point is concerned with a migrant's optimal behavior and his or her response to a change in the exogenous variables. Consider a foreign worker, permitted to immigrate for a certain year, making a decision either to be a permanent migrant or to be a cross-border worker. A cross-border worker must pay travel costs daily, but a permanent migrant must pay only once. Therefore, a foreign worker would like to be a permanent migrant (or cross-border worker) if the travel cost is high (or low) or if the world rate of interest is low (or high) or if their permitted period is extended (or reduced). Applying the results obtained earlier, we can see the influences on the prices and welfare in the host country.

\section{Appendix 1}

With $p_{N}$ being constant, total differentiation of Eqs. 2.1, 2.2, 2.3, and 2.4 with respect to $L_{N}, L_{T}, K_{N}, K_{T}$, and $L_{M}$ yields

$$
\begin{gathered}
p_{N} N^{L L} d L_{N}+p_{N} N^{L K} d K_{N}-T^{L L} d L_{T}-T^{L K} d K_{T}=0, \\
p_{N} N^{K L} d L_{N}+p_{N} N^{K K} d K_{N}-T^{K L} d L_{T}-T^{K K} d K_{T}=0, \\
d L_{T}+d L_{N}-d L_{M}=0, \\
d K_{T}+d K_{N}=0,
\end{gathered}
$$

where $N^{L L} \equiv \partial N^{L} / \partial L_{N}$ and $N^{L K}, N^{K L}, N^{K K}, T^{L L}, T^{L K}$, and $T^{K K}$ are defined in a similar way.

Because $N\left(L_{N}, K_{N}\right)$ and $T\left(L_{T}, K_{T}\right)$ are linearly homogeneous, we apply Euler's theorem and obtain,

$$
\begin{aligned}
& N^{L L} L_{N}+N^{L K} K_{N}=0, \\
& N^{K L} L_{N}+N^{K K} K_{N}=0, \\
& T^{L L} L_{T}+T^{L K} K_{T}=0, \\
& T^{K L} L_{T}+T^{K K} K_{T}=0 .
\end{aligned}
$$

The first two equations of (A2.1) can be expressed as follows by substituting other equations: 


$$
\begin{aligned}
& {\left[\begin{array}{cc}
p_{N} k_{N} N^{L K}+k_{T} T^{L K} & -\left(p_{N} N^{L K}+T^{L K}\right) \\
-\left(p_{N} N^{L K}+T^{L K}\right) & p_{N}\left(1 / k_{N}\right) N^{L K}+\left(1 / k_{T}\right) k_{T} T^{L K}
\end{array}\right]\left[\begin{array}{l}
d L_{T} \\
d K_{T}
\end{array}\right]} \\
& \quad=\left[\begin{array}{c}
k_{N} p_{N} N^{L K} \\
-p_{N} N^{L K}
\end{array}\right] d L_{M} .
\end{aligned}
$$

Let $\Phi$ stand for the determinant of the two-by-two matrix in (A2.3), then $\Phi=$ $\left[\left(k_{T}-k_{N}\right)^{2} / k_{T} k_{N}\right] p_{N} N^{L K} T^{L K}>0$. Therefore,

$$
\begin{gathered}
\frac{d L_{T}}{d L_{M}}=\frac{1}{\Phi} p_{N} N^{L K} T^{L K} \frac{k_{N}-1}{k_{T}}=\frac{k_{N}}{k_{N}-k_{T}}, \\
\frac{d K_{T}}{d L_{M}}=\frac{1}{\Phi} p_{N} N^{L K} T^{L K}\left(k_{T}-k_{N}\right)=\frac{k_{T} k_{N}}{k_{N}-k_{T}} \\
\frac{d L_{N}}{d L_{M}}=1-\frac{d L_{T}}{d L_{M}}=\frac{-k_{T}}{k_{N}-k_{T}} \\
\frac{d K_{N}}{d L_{M}}=-\frac{d K_{T}}{d L_{M}}=\frac{-k_{T} k_{N}}{k_{N}-k_{T}}
\end{gathered}
$$

Hence, $d L_{T} / d L_{M}>(<) 0, d K_{T} / d L_{M}>(<) 0, d L_{N} / d L_{M}<(>) 0$, and $d K_{N} / d L_{M}<$ $(>) 0$, according to $k_{T}-k_{N}<(>) 0$. Thus, $d T / d L_{M}>(<) 0$ and $d N / d L_{M}<(>) 0$ if $k_{T}-k_{N}<(>) 0$. The sign of $d L_{T} / d L_{M}$ is opposite to that of $d L_{N} / d L_{M}$, implying that in view of the third equation of (A2.1), $d L_{N} / d L_{M}$ must be greater than unity when $d L_{N} / d L_{M}>0$.

Next, holding $L_{M}$ constant, total differentiation of Eqs. 2.1, 2.2, 2.3, and 2.4 with respect to $p_{N}, L_{N}, L_{T}, K_{N}$, and $K_{T}$ gives

$$
\begin{gathered}
N^{L} d p_{N}+p_{N} N^{L L} d L_{N}+p_{N} N^{L K} d K_{N}-T^{L L} d L_{T}-T^{L K} d K_{T}=0 \\
N^{K} d p_{N}+p_{N} N^{K L} d L_{N}+p_{N} N^{K K} d K_{N}-T^{K L} d L_{T}-T^{K K} d K_{T}=0 \\
d L_{T}+d L_{N}=0 \\
d K_{T}+d K_{N}=0 .
\end{gathered}
$$

The first two equations of (A2.4) can be expressed, by substituting the other two equations of (A2.4) and (A2.2), as

$$
\begin{aligned}
& {\left[\begin{array}{cc}
p_{N} k_{N} N^{L K}+k_{T} T^{L K} & -\left(p_{N} N^{L K}+T^{L K}\right) \\
-\left(p_{N} N^{L K}+T^{L K}\right) & p_{N}\left(1 / k_{N}\right) N^{L K}+\left(1 / k_{T}\right) k_{T} T^{L K}
\end{array}\right]\left[\begin{array}{c}
d L_{T} \\
d K_{T}
\end{array}\right]} \\
& =\left[\begin{array}{l}
-N^{L} \\
-N^{K}
\end{array}\right] d p_{N},
\end{aligned}
$$

and 


$$
\begin{gathered}
\frac{d L_{T}}{d p_{N}}=\frac{1}{\Delta}\left|\begin{array}{cc}
-N^{L} & -\left(p_{N} N^{L K}+T^{L K}\right) \\
-N^{K} & p_{N}\left(1 / k_{N}\right) N^{L K}+\left(1 / k_{T}\right) k_{T} T^{L K}
\end{array}\right|, \\
\frac{d K_{T}}{d p_{N}}=\frac{1}{\Delta}\left|\begin{array}{cc}
p_{N} k_{N} N^{L K}+k_{T} T^{L K} & -N^{L} \\
-\left(p_{N} N^{L K}+T^{L K}\right) & -N^{K}
\end{array}\right|,
\end{gathered}
$$

where $\Delta$ is the determinant of the left-hand-side matrix of (A2.5). To obtain the result of Eq. 2.8, it is necessary to use (A2.2) to substitute $T^{L L}=k_{T} T^{L K}$, and then substitute the expressions for $d L_{T} / d p_{N}$ and $d K_{T} / d P_{N}$, given above.

\section{Appendix 2}

Following Wong (1995), let us define the gross domestic product (GDP) function as

$$
g(p, v)=\operatorname{Max}_{Q}\{p Q: \Gamma(Q, v) \leq 0\}
$$

where $v$ denotes the $m$-dimensional vector of factor endowments, $Q$ denotes the $n$ dimensional vector of outputs, $p$ denotes the $n$-dimensional vector of goods prices, and $\Gamma(Q, v) \leq 0$ denotes the production possibility set of the economy. Let $v^{0}$ be factor endowment before immigration and $v^{e}$ represent the number of factors flowing into and working in the economy. The total factors available to domestic firms are $v^{t}=v^{0}+v^{e}$.

First, let us consider the case of a small country and the scenario where every good is tradable. Then, the vector of goods prices can be expressed as $p^{w}$, which remains constant after international factor mobility. The profit maximization behavior of each firm can be interpreted as expenditure minimization behavior, and this implies a minimization of payments to factors. Thus, factor prices before migration, $w^{0}$, can be expressed as

$$
g\left(p^{w}, v^{0}\right)=\operatorname{Min}_{w}\left\{w v: p_{i}^{w} \leq c_{i}\left(w^{0}\right), i=1, \ldots, n\right\}=w^{0} v^{0},
$$

where $c_{i}(w)$ denotes the unit cost function of good $i$. Similarly, factor prices after immigration, $w^{1}$, can be expressed as

$$
g\left(p^{w}, v^{t}\right)=w^{1} v^{t}
$$

Remember that $w^{0}$ is the vector of factor prices that minimize expenditure to employed factors $v^{0} ; w^{1}$ is the vector prices for factors $v^{t}$, not $v^{0}$. Thus, we can assert that

$$
w^{0} v^{0}<w^{1} v^{0}
$$


under the assumption that $w^{1} \neq w^{0}$ and a strictly convex production possibility set. Now, let us define the indirect utility function of domestic residents as

$$
V^{0}(p, v, b)=\operatorname{Max}_{C}\{u(C): p C \leq g(p, v)-b\}
$$

where $C$ is the aggregate consumption bundle, $u(C)$ is the social welfare level, and $b$ is income transfers to immigrants. Before immigration, the factor endowment is $v^{0}$, and payment for those employed factors can be expressed as $v^{0} w^{0}$. Thus, the utility level of domestic residents before immigration yields $V^{0}\left(p^{w}, v^{0}, 0\right)$. On the other hand, after immigration, the factor endowment is $v^{t}$, and payment for those employed factors can be expressed as $v^{t} w^{t}$. In this case, there exists transfer $b$, which equals $w^{1} v$. Thus, the utility level of domestic residents after immigration yields $V^{0}\left(p^{w}, v^{t}, b\right)$.

Equation A2.6 implies that the income of domestic workers will increase after immigration. Bearing in mind that the price vector remains constant and indirect utility is a strictly increasing function of income, we obtain

$$
V^{0}\left(p^{w}, v^{0}, 0\right)<V^{0}\left(p^{w}, v^{t}, b\right),
$$

which implies that immigration enhances the welfare of domestic residents.

\section{References}

Bhagwati, J. N., \& Brecher, R. A. (1980). National welfare in an open economy in the presence of foreign-owned factors of production. Journal of International Economics, 10, 103-115.

Bhagwati, J. N., \& Hamada, K. (1982). Tax policy in the presence of emigration. Journal of Public Economics, 18, 291-317.

Bhagwati, J. N., Schatz, K. W., \& Wong, K. Y. (1984). The West German gastarbeiter system of immigration. European Economic Review, 26, 277-294.

Bohning, W. R. (1984). Studies in international labor migration. New York: St. Martins Press.

Borjas, G. J. (1994). The economics of immigration. Journal of Economic Literature, 32, 16671717.

Chau, N. H. (1997). The pattern of migration with variable migration cost. Journal of Regional Science, 37, 35-54.

de Falleur, M., \& Vandeville V. (1994). Cross-border workers flows in Europe: Facts and determinants. Paper presented at the 34th European Congress of the Regional Science Association, Groningen.

Djajić, S. (1986). International migration, remittances and welfare in a development economy. Journal of Development Economics, 21, 229-234.

Djajić, S. (1989). Migrants in a guest-worker system - a utility maximizing approach. Journal of Development Economics, 31, 327-339.

Djajić, S., \& Milboune, R. (1988). A general equilibrium model of guest-worker migration - the source country perspective. Journal of International Economics, 25, 335-351.

Dustmann, C. (1997). Return migration, uncertainty and precautionary savings. Journal of Development Economics, 52, 295-316. 
Dustmann, C., Frattini, T., \& Preston, I. P. (2013). The effect of immigration along the distribution of wages. Review of Economic Studies, 80, 145-173.

Hill, J. K. (1987). Immigration decisions concerning duration of stay and migration frequency. Journal of Development Economics, 25, 221-234.

Jones, R. W. (1965). The structure of simple general equilibrium models. Journal of Political Economy, 73, 557-572.

Kau, J. B., \& Sirmans, C. F. (1977). The influence of information cost and uncertainty on migration: A comparison of migrant types. Journal of Regional Science, 17, 89-96.

Kondoh, K. (1999). Permanent migrants and cross-border workers: The effects on the host country. Journal of Regional Science, 39, 467-478.

Lundahl, M. (1985). International migration, remittances and real incomes: Effects on the source country. Scandinavian Journal of Economics, 87, 647-657.

Mandelman, F., \& Zlate, A. (2012). Immigration, remittances and business cycles. Journal of Monetary Economics, 59, 196-213.

McCall, B. P., \& McCall, J. J. (1987). A sequential study of migration and job search. Journal of Labor Economics, 5, 452-476.

Mueller, C. F. (1982). The economics of labor migration: A behavioral analysis. New York: Academic.

O’Connell, P. G. J. (1997). Migration under uncertainty: 'Try your luck' or 'wait and see'. Journal of Regional Science, 37, 331-347.

Ottaviano, G. I. P., \& Peri, G. (2012). Rethinking the effect of immigration on wages. Journal of European Economic Association, 10, 152-197.

Quibria, M. G. (1988). A note on international migration, non-traded goods and economic welfare in the source country. Journal of Development Economics, 28, 377-387.

Quibria, M. G. (1989). International migration and real wages: Is there any neo-classical ambiguity? Journal of Development Economics, 28, 177-183.

Rivera-Batiz, F. L. (1982). International migration, non-traded goods and economic welfare in the source country. Journal of Development Economics, 11, 81-90.

Rivera-Batiz, F. L. (1983). The economics of the 'to and fro' migrant: Some welfare theoretical considerations. Scandinavian Journal of Economics, 85, 403-413.

Rivera-Batiz, F. L. (1984). International migration, non-traded goods and economic welfare in a two class economy. Journal of Development Economics, 16, 325-330.

Shen, I., Docquier, F., \& Rapoport, H. (2010). Remittances and inequality: A dynamic migration model. Journal of Economic Inequality, 8, 197-220.

Thompson, H. (1984). International migration, non-traded goods and economic welfare in the source country: A comment. Journal of Development Economics, 16, 321-324.

Waldorf, B. S., \& Esparza, A. (1991). A parametric failure time model of international return migration. Papers in Regional Science, 70, 419-438.

Wong, K. Y. (1995). International trade in goods and factor mobility. Cambridge, MA: The MIT Press. 